\title{
Assessment of Mechanical and Tribological Properties of Diamond-Like Carbon Coatings on the Ti13Nb13Zr Alloy
}

https://doi.org/10.1515/eng-2020-0043

Received Dec 12, 2019; accepted Mar 25, 2020

\begin{abstract}
The paper presents the results of tests on the geometric structure of the surface, hardness and tribological tests of coatings produced by the method of physical vapor deposition (PVD) on the Ti13Nb13Zr alloy. Hardness was determined using MCT $^{3}$ from Anton Paar, by instrumental indentation. A diamond indenter with Berkovich geometry was used for the measurement. Model tribological tests were carried out in reciprocating motion under conditions of technically dry friction, friction with lubrication of synovial fluid and Ringer's solution. The counter-sample in the tested friction nodes was a ball of $\mathrm{Al}_{2} \mathrm{O}_{3}$ with a diameter of $6 \mathrm{~mm}$. Nanometer hardness measurements showed that as a result of the diamond-like carbon coating (DLC), the hardness increased by an 7-fold. The lowest friction coefficients among all tested friction nodes were obtained for the material combination Ti13Nb13Zr a-C: $\mathrm{H}-\mathrm{Al}_{2} \mathrm{O}_{3}$ regardless of the conditions of testing. In the case of technically dry friction, the coefficient of friction decreased by $80 \%$, synovial fluid by $70 \%$, and in the case of Ringer's solution by $88 \%$ compared to the results obtained for Ti13Nb13Zr.
\end{abstract}

Keywords: adhesion, DLC - coating, coefficient of friction, hardness, PVD

\section{Introduction}

In recent years there was a significant progress both in the testing and application subject regarding the amorphous carbon. The amorphous carbon might be the mixture of the

\footnotetext{
${ }^{\star}$ Corresponding Author: Katarzyna Piotrowska: Kielce University of Technology, Faculty of Mechatronics and Mechanical Engineering, al. 1000-Lecia P. P. 7, Poland; Email: kpiotrowskapsk@wp.pl Arkadiusz Granek: Hospital MSWiA, ul. Ogrodowa 11, 25-024 Kielce, Poland

Monika Madej: Kielce University of Technology, Faculty of Mechatronics and Mechanical Engineering, al. 1000-Lecia P. P. 7, Poland
}

atoms with the $\mathrm{sp}^{3}, \mathrm{sp}^{2}$ or even $\mathrm{sp}^{1}$ bonds, with the possibility of the hydrogen presence. Amorphous carbonic materials are characterized with high variety of structure, and their properties mainly due to the type and parameters of their production [1]. However, one of the important factors crucial regarding their properties is a $\mathrm{sp}^{3}$ bonds existing in diamond's structure - responsible for a high hardness, and $\mathrm{sp}^{2}$ bonds - existing in graphite, resulting in excellent lubricating properties. Amorphous carbon with high contents of diamond sp3 bonds is known as DLC [2].

Due to their characteristics, diamond-like coatings are becoming increasingly important in today's industry. Very good mechanical properties such as high elastic modulus, fracture resistance, chemical stability and low friction coefficient enable their use in various branches of industry. These coatings are used in automotive, aviation, chemical and medical industries [3-7].

The need to meet the requirements of the current market has resulted in a rapid development of manufacturing techniques both in terms of materials and construction. The deposited layers are characterized by increasing hardness and resistance to frictional wear. There is also a tendency of continuous reduction of their thickness and application of multilayer coatings. One of the fastestwearing trends are modern techniques of surface engineering, including the formation of thin, hard diamond-like DLC coatings. A limitation in the widespread use of DLC coatings is the lack of comprehensive knowledge about their properties. The same layers applied with different methods and different parameters of the deposition process may have completely different properties. The selection of a anti-wear coating for a specific application requires detailed knowledge of its mechanical and tribological properties. Therefore, it is necessary to carry out tests of the coating-substrate systems [8-10]. The evaluation of tribological properties is carried out on the basis of the friction and wear characteristics, conducted under conditions of technically dry friction and friction with lubricating agents. In order to determine the hardness, elastic modulus and adhesion of the coating to the substrate, inden- 


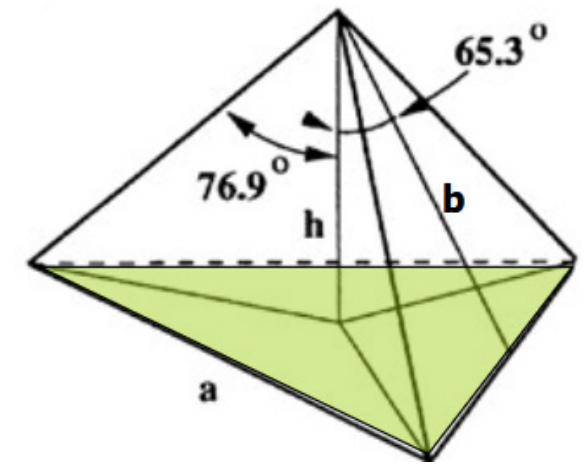

(a)

Figure 1: Geometry of Berkovich indenter

tation and scratching tests are used. The results obtained during these tests will facilitate the selection of the coating and the development of an optimal technological process of deposition in the aspect of its application.

\section{Materials and methods}

A single-layer a-C:H diamond-like coating applied at the temperature of $250^{\circ} \mathrm{C}$ using physical vapor deposition method (PVD) was investigated. The substrate was titanium alloy Ti13Nb13Zr.

The nano-hardness of the coating was determined using the Anton Paar UNHT ultra-nano hardness tester by means of instrumental indentation method. The test consisted in pressing into the tested material of an indenter of Berkovich geometry (Figure 1 ) with a radius of $R_{i}=100 \mathrm{~nm}$ [11]. The measurement was made at a nominal load force of $10 \mathrm{mN}$ and a buildup speed of $20 \mathrm{mN} / \mathrm{min}$.

The applied research technique enabled precise recording of the load-indentation depth curve. Mechanical parameters, e.g. elastic modulus, were determined taking into account the inclination of the tangent to the initial part of the load curve, according to the Olivier-Pharr method based on the relation [12-14]:

$$
E=\frac{E_{i}\left(1-v^{2}\right)}{\frac{2^{\star} \sqrt{A_{p}}}{\sqrt{\pi^{\star} S}} \star E_{i}-\left(1-v_{i}{ }^{2}\right)}
$$

where:

$E_{i}, v_{i}$ - indenter modulus and Poisson's ratio

$E, v$ - sample modulus and Poisson's ratio

$S$ - stiffness

$A_{p}$ - projected contact area

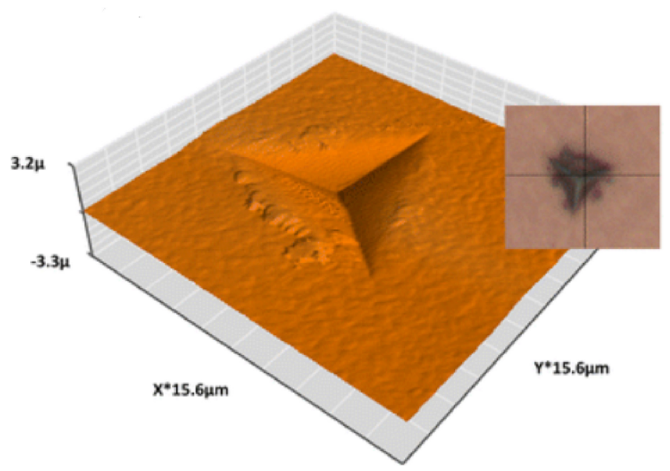

(b)

Nano-hardness is the ratio of the load force $P_{\max }$ to the surface of the imprint after relieving $A$ :

$$
H V=\frac{P_{\max }}{A}
$$

In addition, the load-relief curve provides information about the deformation of the material during the test and allows the determination of such parameters as: total work (total field under the recorded load-relief curve), elastic deformation work (field under the relief curve) and plastic deformation work (field inside the load-displacement curve) [15].

During the test it is possible to measure the geometric parameters of a scratch, perform its microscopic analysis and record the acoustic emission during cracking of the coating [16]. The test was carried out on an $\mathrm{MCT}^{3}$ device manufactured by Anton Paar. It consisted in making a scratch on the surface of the sample with a diamond indenter Rockwell C (Figure 2) under a load of normal force $\mathrm{F}_{N}$. Destruction of the surface layer may have the character of cohesive cracks - perpendicular to the direction of the indenter motion or adhesive cracks - manifested as local delaminations of the coating [9]. The test was performed at an increasing load force of $0.03-15 \mathrm{~N}$, table travel speed

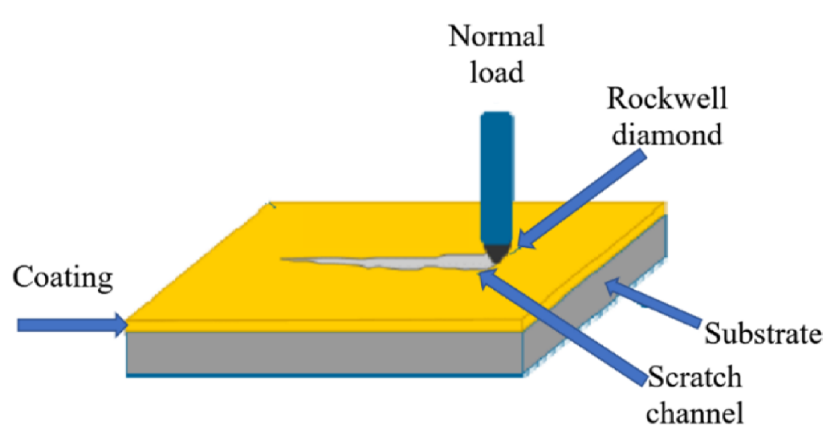

Figure 2: A schematic illustrating w scratch test on a coated sample 
of $1.2 \mathrm{~mm} / \mathrm{min}$, table load speed of $10 \mathrm{~N} / \mathrm{min}$ and scratch length of $3 \mathrm{~mm}$.

The use of diamond-like coatings in various branches of industry also forces the need to carry out tests of resistance to wear through friction together with the determination of the friction coefficient. The tribological tests were conducted using a TRB ${ }^{3}$ ball-on disc system. In the TRB ${ }^{3}$ tribometer, a rotating ball made of $\mathrm{Al}_{2} \mathrm{O}_{3}$ (diameter $=6$ $\mathrm{mm}$ ) was pressed against a test sample (Ti13Nb13Zr with and without an a-C:H-type diamond-like carbon coating), applying a amplitude $1 \mathrm{~Hz}$ and a load of $10 \mathrm{~N}$. The number of cycles was 10000 . The specimens were tested under dry friction conditions (TDF) and under lubricated friction conditions using Ringer solution (RS) and synovial fluid (SF). The tests were performed in laboratory conditions at a relative humidity of $50 \pm 5 \%$ and a temperature of $23 \pm 1^{\circ} \mathrm{C}$.

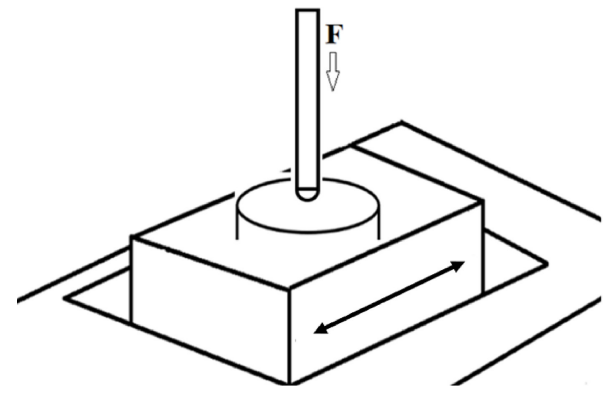

Figure 3: View of ball-on-disc

\section{Discussion and results}

The thickness of the diamond-like coating was measured at using a Phenom XL scaning microscope. Figure 4a shows a view of DLC coatings in cross-section together with its thickness measured. The green arrow indicates the direction of the linear analysis. The resultant DLC coating has a thickness of about $1.74 \mu \mathrm{m}$. During follow-up there were no defects and discontinuities structure. EDS analysis of a coating a-C:H (Figure $4 \mathrm{~b}$ ) showed that it consists of the subcoatings. The layer on the surface is mainly the carbon. An interlayer of thickness $0.98 \mu \mathrm{m}$ lying between the substrate and the layer of a-C:H forms subcoat consisting essentially of wolfram with a small extent of chromium. Chromium and tungsten interlayer are responsible for increasing the adhesion of the DLC coating to the substrate.

Figure 5 presents the load-relief curves recorded when the indenter is pushed into the tested materials. Based on the measurement of indenter penetration depth and the knowledge of the geometry of the imprint, the mechanical parameters discussed above were determined. Table 1 shows their averaged values from 10 measurements.

The curves shown in Figure 5 indicate high plasticity of the substrate and elasticity of the a-C: $\mathrm{H}$ coating. This is evidenced by the inclination of the indentation curve and the values of contact surfaces, total work, elastic and plastic deformation work.

Table 1: Mechanical parameters

\begin{tabular}{cccc}
\hline Parameters & Unit & \multicolumn{2}{c}{ Sample } \\
\cline { 3 - 4 } & & Ti13Nb13Zr & $\begin{array}{c}\text { Ti13Nb13Zr } \\
\text { a-C:H }\end{array}$ \\
\hline Indentation hardness & $\mathrm{GPa}$ & 3.5 & 25.5 \\
{$\left[\mathrm{H}_{I T}\right]$} & & & \\
Vickers Hardness $[\mathrm{HV}]$ & $\mathrm{HV}$ & 331 & 2328 \\
Young Modulus $\left[\mathrm{E}^{\star}\right]$ & $\mathrm{GPa}$ & 143 & 209 \\
Contact area $\left[\mathrm{A}_{p}\right]$ & $\mu \mathrm{m}^{2}$ & 2.822 & 4.292 \\
Plastic work $\left[\mathrm{W}_{\text {plast }}\right]$ & $\mathrm{pJ}$ & 1035.2 & 153.2 \\
Elastic work $\left[\mathrm{W}_{\text {elast }}\right]$ & $\mathrm{pJ}$ & 252.6 & 460.2 \\
Total work $\left[\mathrm{W}_{\text {tot }}\right]$ & $\mathrm{pJ}$ & 1287.8 & 613.5 \\
\hline & & &
\end{tabular}

As a result of application of the diamond-like coating, there was an 7-fold increase in hardness, almost 2-fold increase in elastic modulus, and a reduction in creep properties. This is proven by a decrease in the value of the increment in the penetration depth under the set load. In addition, the use of a diamond-like coating of a-C:H type caused a double decrease in the value of the total work of indentation $\mathrm{W}_{\text {tot }}$ and its components $\mathrm{W}_{\text {plast }}$ and $\mathrm{W}_{\text {elast }}$, which indicates a decrease in the susceptibility of the coating to deformation as a result of operating loads.

The measure of the adhesion of a layer to the substrate is the critical force that first causes the $\mathrm{L}_{C 1}$ coating to crack and then destroys it $\left(\mathrm{L}_{C 2}\right)$. Figure 6 presents the results of the scratch test. The critical force was evaluated on the basis of microscopic observations and registered changes in acoustic emission. The values of the forces causing the first $\mathrm{L}_{C 1}$ chip and the delamination of the $\mathrm{L}_{C 2}$ layer are summarized in Table 2.

Table 2: The adhesion tests of diamond-like carbon coating

\begin{tabular}{cccccc}
\hline & \multicolumn{4}{c}{ Measurement number } \\
& $\mathbf{1}$ & $\mathbf{2}$ & $\mathbf{3}$ & Mean & Standard \\
& & & & & deviation \\
\hline $\mathrm{L}_{\mathrm{C1}}[\mathrm{N}]$ & 2.87 & 3.02 & 2.98 & 2.95 & 0.06 \\
$\mathrm{~L}_{C 2}[\mathrm{~N}]$ & 9.63 & 9.87 & 10.1 & 9.86 & 0.19 \\
\hline
\end{tabular}




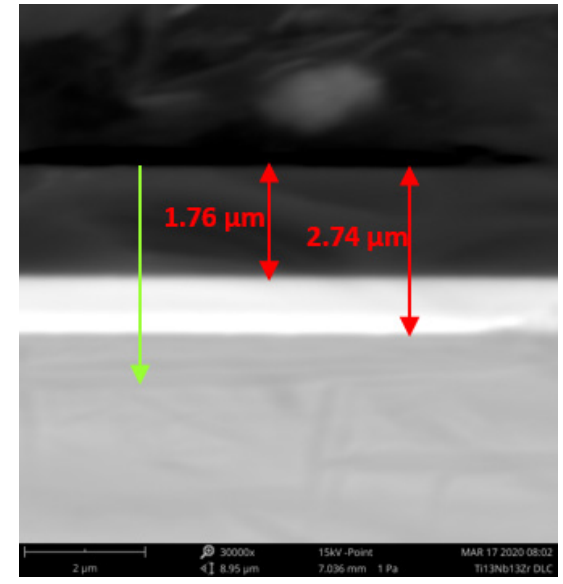

(a)

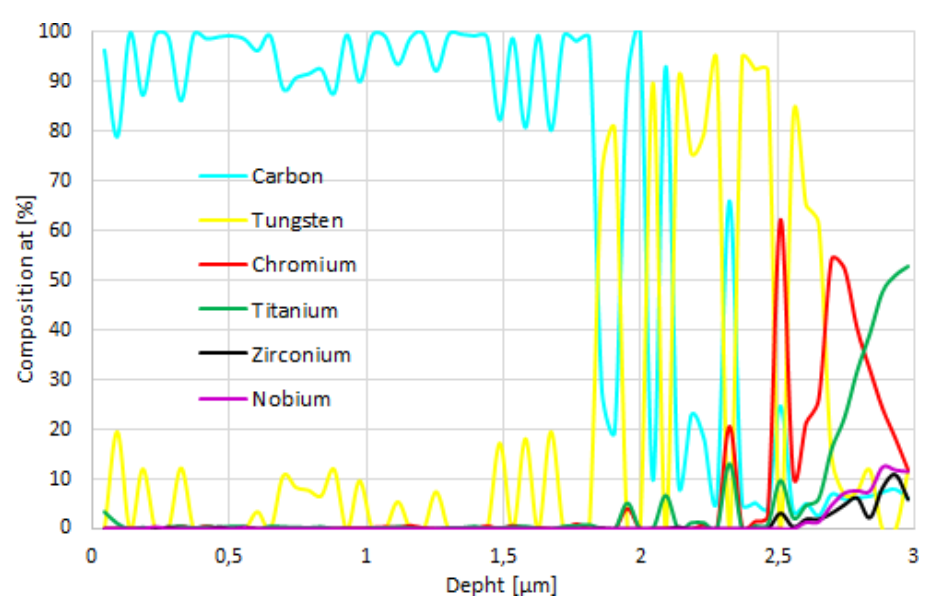

(b)

Figure 4: The thickness of DLC coatings (a), distribution of elements from the surface down into the a-C:H coating atomic percentage (b)

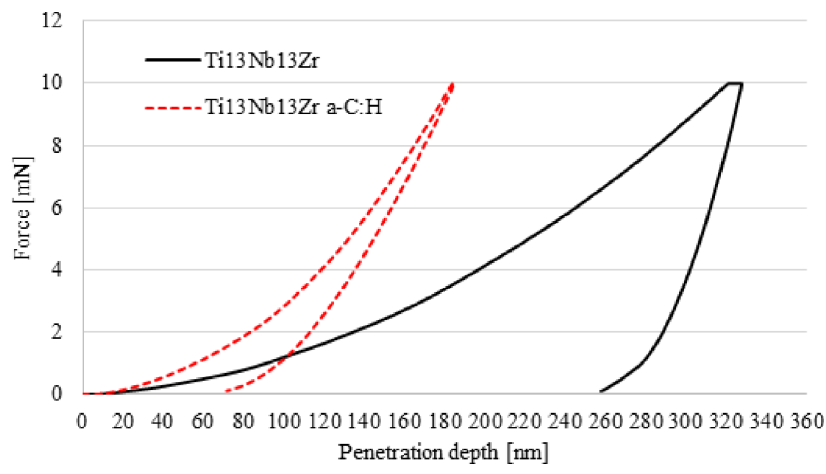

Figure 5: Load - penetration depth curves from indentation tests

Tests of adhesion of the diamond-like layer showed that the mean value of the critical force $\mathrm{L}_{C 1}$ was $2.95 \mathrm{~N}$ and $\mathrm{L}_{C 2}-9.86 \mathrm{~N}$. The microscopic analysis showed that the destruction of the surface layer had the character of adhesive cracks. This type of cracks is visible in the form of local delaminations on the sides of the scratch or tearing off the coating in front of the indenter.

The results of friction tests were summarized on a graph of the friction coefficient - $\mu$ (Figure 7) of test elements depending on the types of materials, friction pairs and lubricants used.

Figure 7 indicates that the best tribological characteristics were obtained for the material combination of Ti13Nb13Zr with a DLC - $\mathrm{Al}_{2} \mathrm{O}_{3}$ coating using Ringer's solution as a lubricant. In the case of technically dry friction and friction with lubrication using synovial fluid solution, the recorded values of the friction coefficient were comparable. They were respectively 0.11 and 0.12 . In comparison with the Ti13Nb13Zr substrate they were $80 \%$ lower for TDF, $88 \%$ lower for RS and $70 \%$ lower for SF.
After tribological tests, surface morphology observation (Figure 8-13) and analysis of the geometric structure of the surface were conducted (Figure 14-15). The maximum depth and the area of the friction surface determined on the basis of the generated profile of the worn out surface (after tribological tests) were taken as the measure of the sample's wear (Figure 16).

Analysis of the surface of the wear trace (Figures 1415) indicates that for Ti13Nb13Zr during technically dry friction, friction using Ringer's solution and synovial fluid, the dominant wear mechanism is abrasive wear. This is due to the different properties of the materials from which the friction components have been made. The ball hardness with $\mathrm{Al}_{2} \mathrm{O}_{3}$ is several times higher than the Ti13Nb13Zr titanium alloy. The scratches and furrows visible in the SEM images were created due to the movement of loose wear products in the friction area. In the case a single-layer a-C:H diamond-like coating, the trace of wear was invisible.

Test results of the geometric structure of the surface after tribological tests shows that the diamond-like coating has a high resistance to abrasion. This is evidenced by the very small area of the wear field (Figure 16). In the case of the Ti13Nb13Zr substrate, the lowest wear was observed in tests in which the Ringer's solution was used. It was lower by $5 \%$ and $15 \%$ respectively in comparison with TDF and SF. 


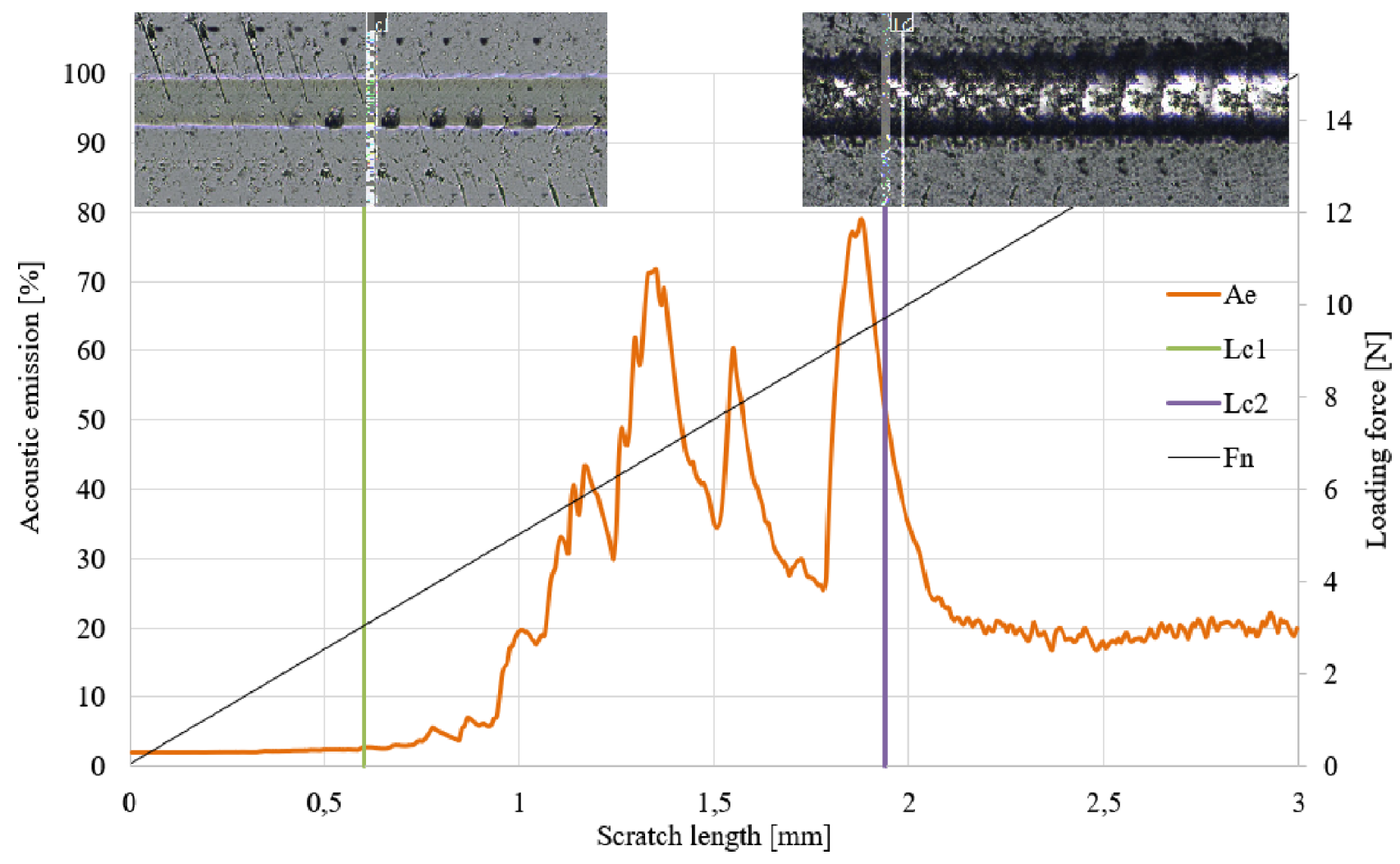

(a)

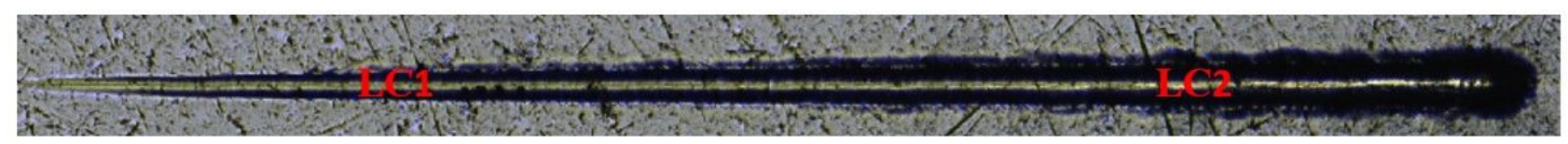

(b)

Figure 6: Scratch test results a) graph of variation of loading force and acoustic emission, b) scratch track: first critical load ( $\left.\mathrm{L}_{C 1}\right)$, second critital load $\left(\mathrm{L}_{\mathrm{C} 2}\right)$

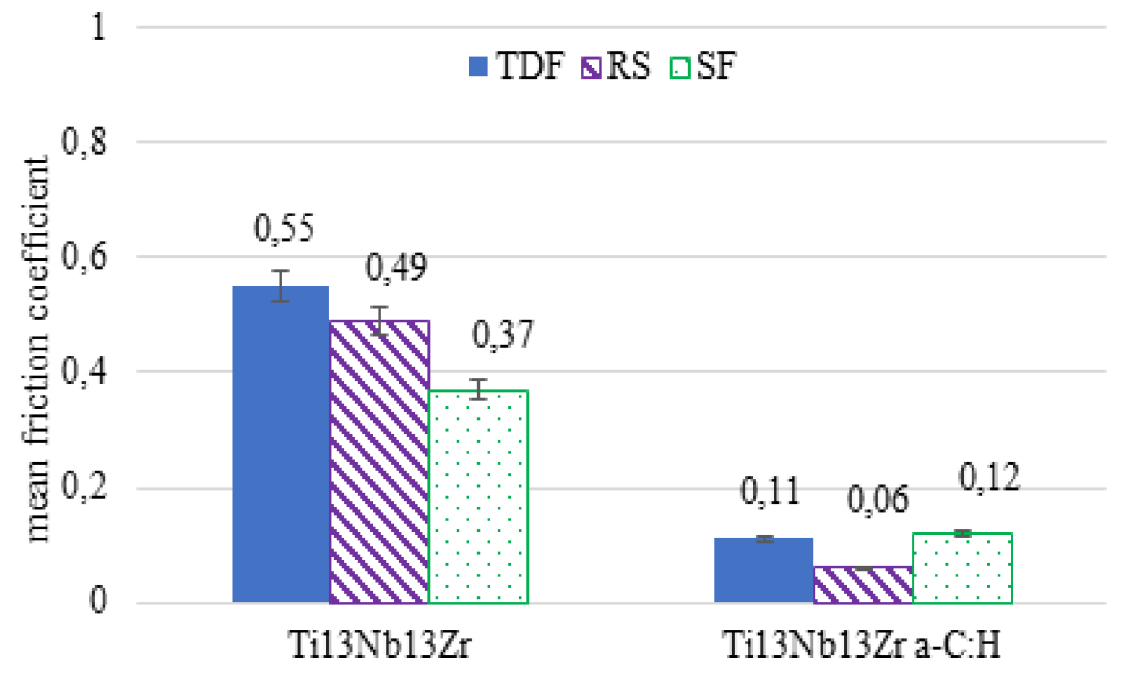

Figure 7: Mean coefficient of friction during: technical dry friction (TDF), Ringer solution (RS) and synovial fluid (SF) 


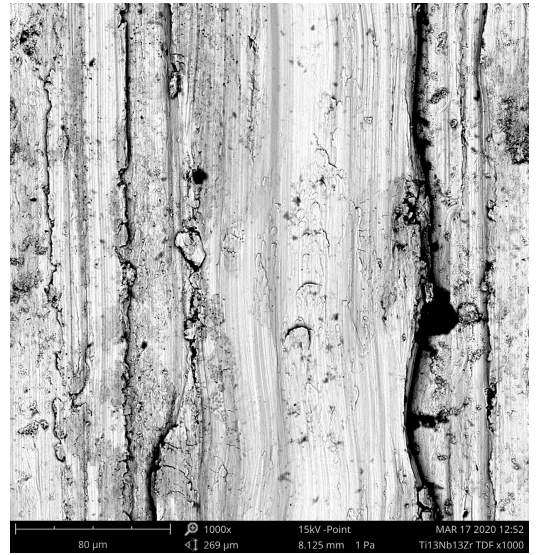

(a) $\mathrm{x} 1000$

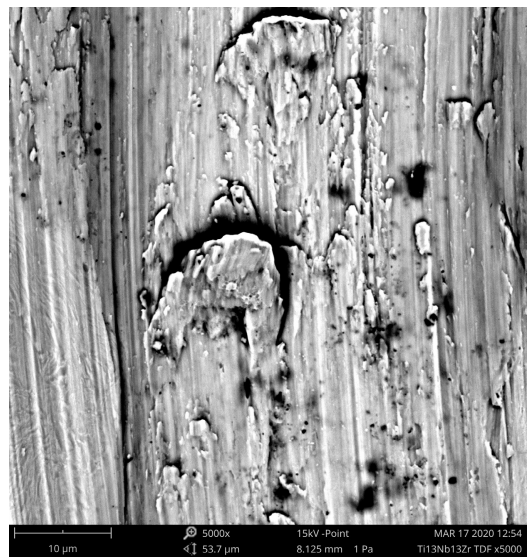

(b) $\times 5000$

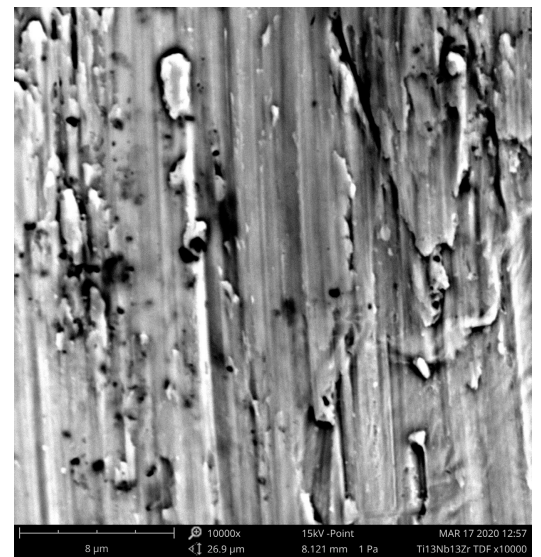

(c) $\times 15000$

Figure 8: Surface morphology of the wear traces after techncal dry friction (TDF) for Ti13Nb13Zr

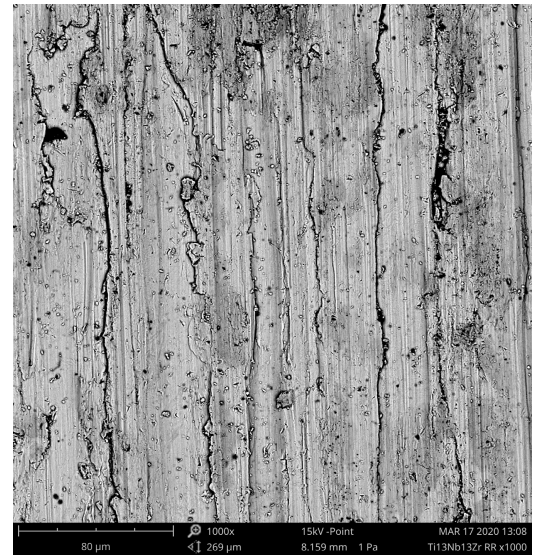

(a) $\mathrm{x} 1000$

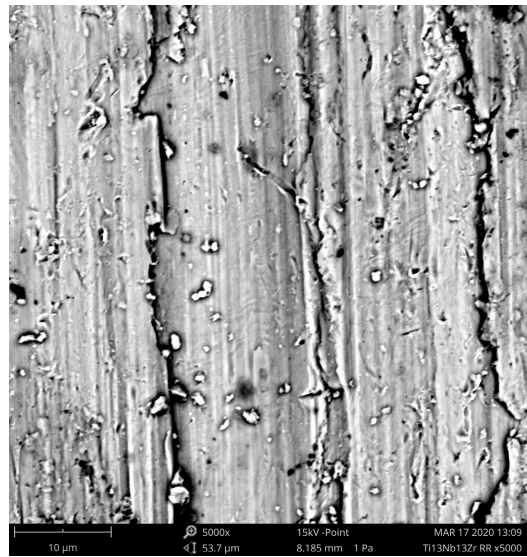

(b) $\times 5000$

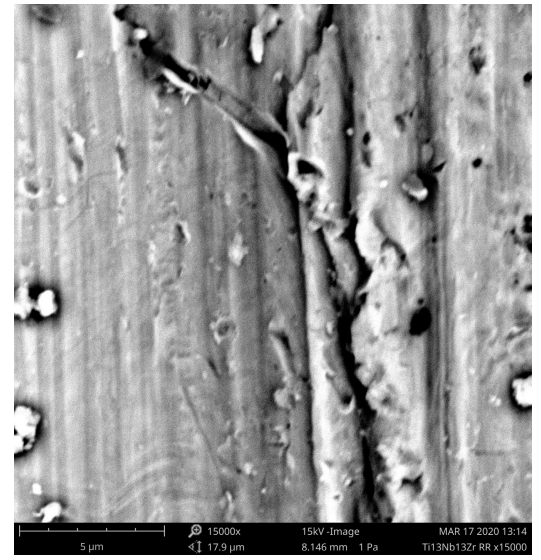

(c) $\times 15000$

Figure 9: Surface morphology of the wear traces after friction with Ringer's solution (RS) for Ti13Nb13Zr

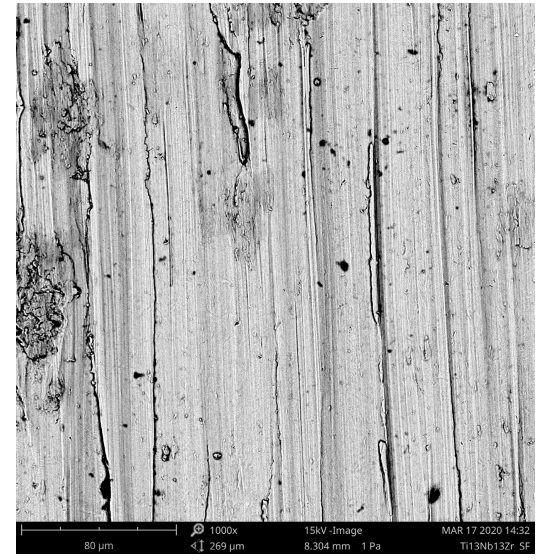

(a) $\mathrm{x} 1000$

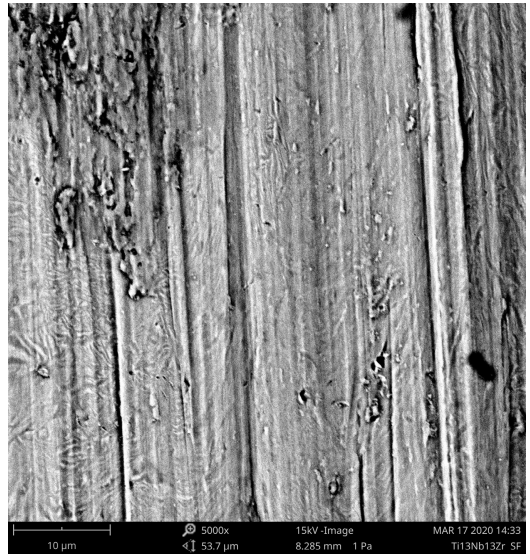

(b) $\mathrm{x} 5000$

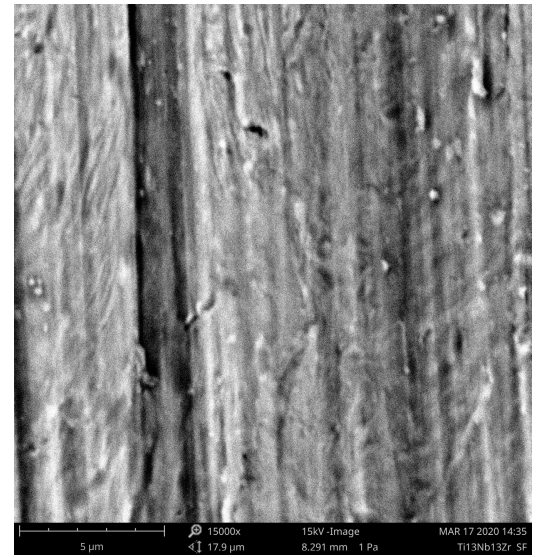

(c) $\times 15000$

Figure 10: Surface morphology of the wear traces after friction with synovial fluid (SF) for Ti13Nb13Zr 


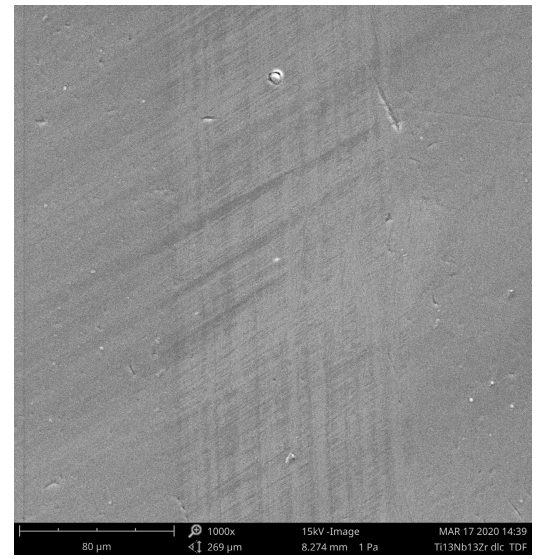

(a) $\times 1000$

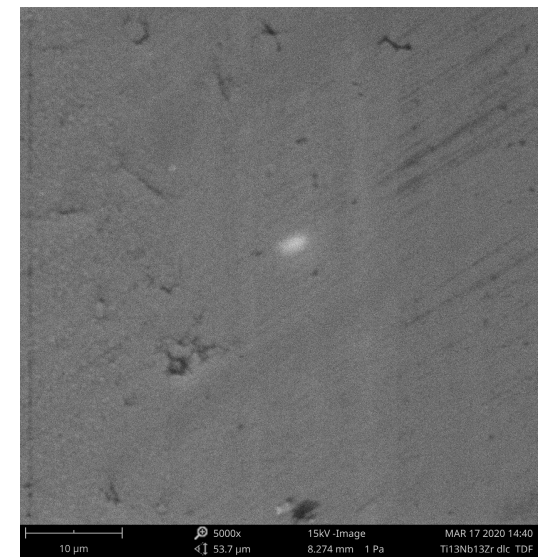

(b) $\mathrm{x} 5000$

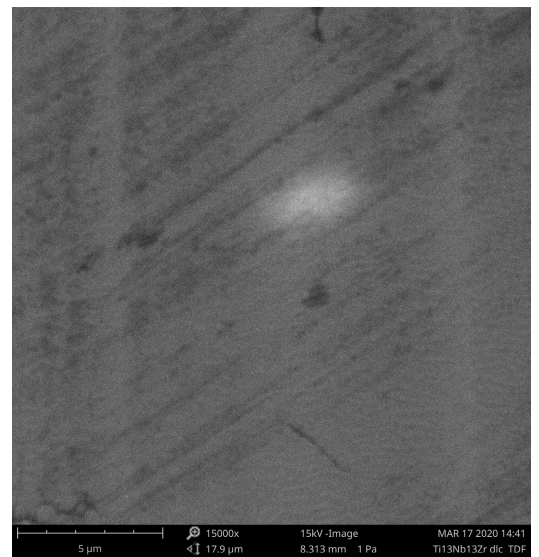

(c) $\mathrm{x} 15000$

Figure 11: Surface morphology of the wear traces after techncal dry friction (TDF) for Ti13Nb13Zr a-C:H

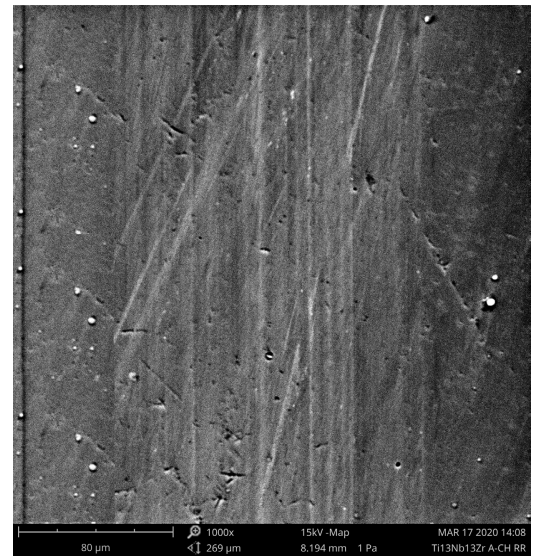

(a) $\times 1000$

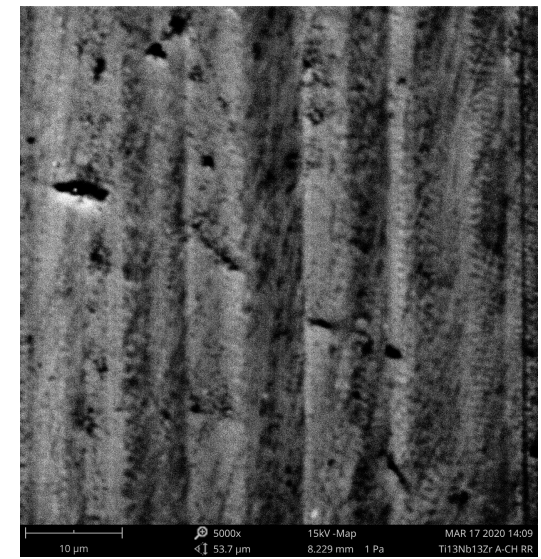

(b) $\mathrm{x} 5000$

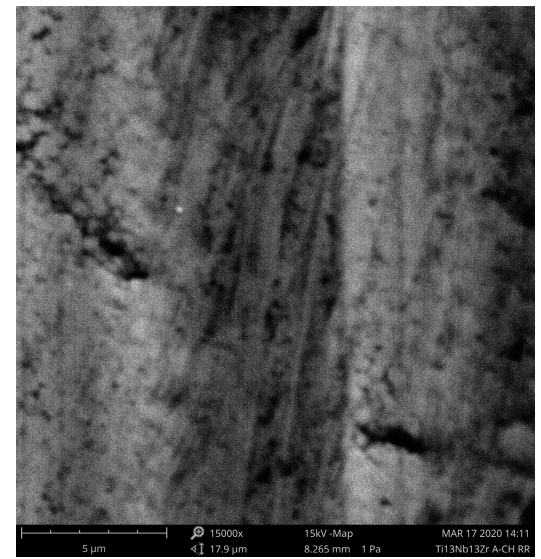

(c) $\mathrm{x} 15000$

Figure 12: Surface morphology of the wear traces after friction with Ringer's solution (RS) for Ti13Nb13Zr a-C:H

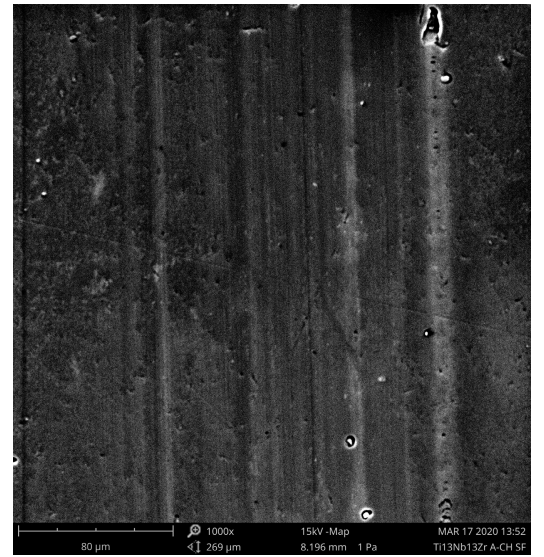

(a) $\mathrm{x} 1000$

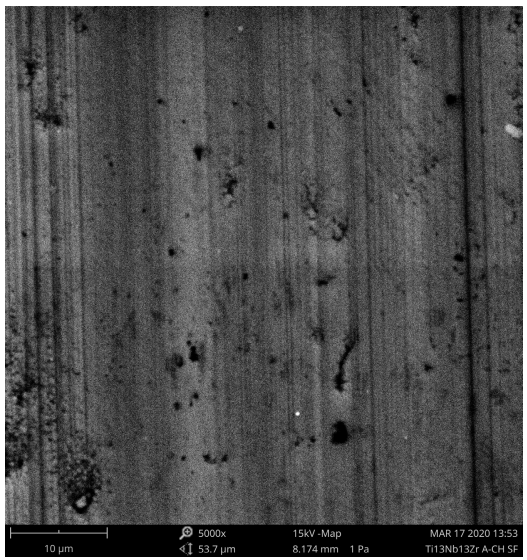

(b) $\mathrm{x} 5000$

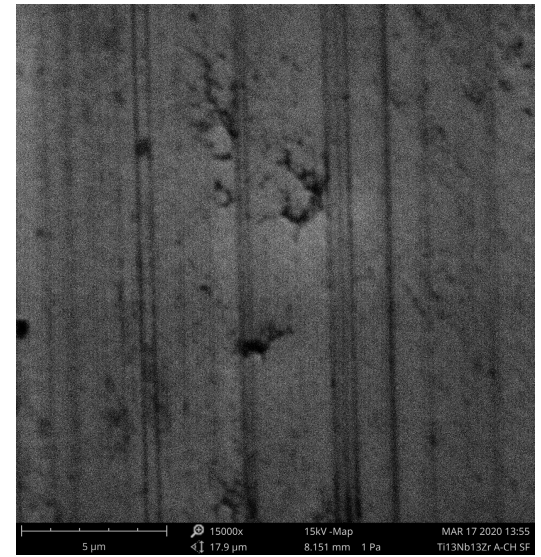

(c) $\mathrm{x} 15000$

Figure 13: Surface morphology of the wear traces after friction with synovial fluid (SF) for Ti13Nb13Zr a-C:H 

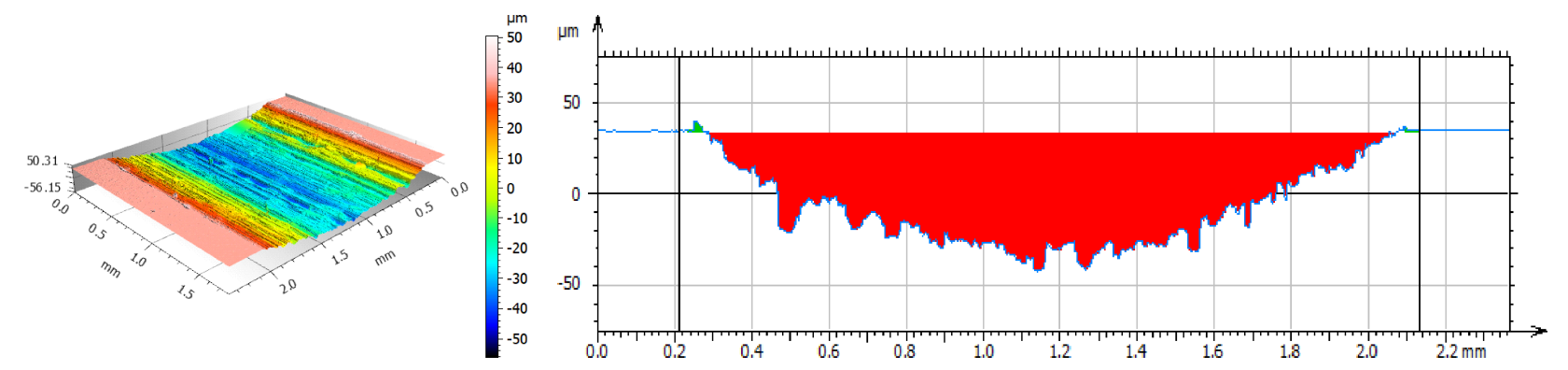

(a)
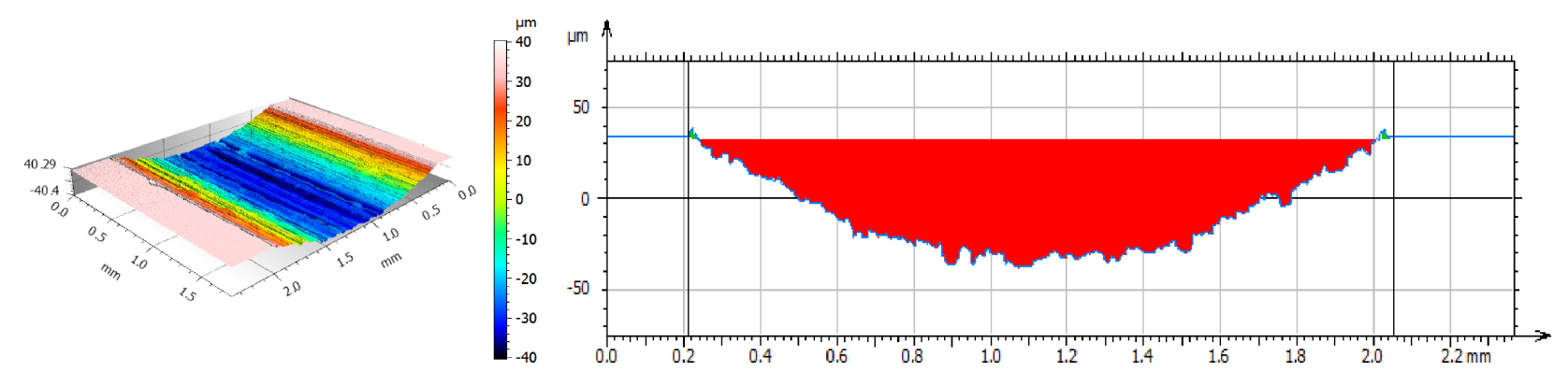

(b)
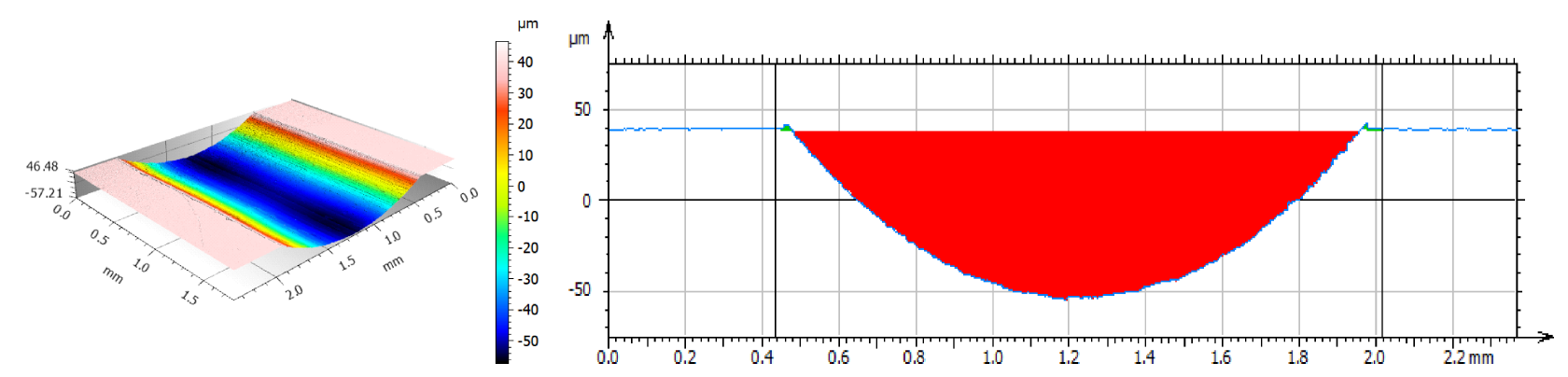

(c)

Figure 14: The isometric image of the trace of wear and the wear profile in a cross-section for Ti13Nb13Zr a) TDF, b) RS, c) SF 


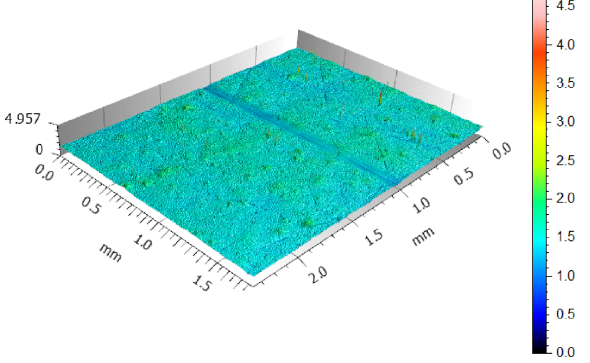

(a)

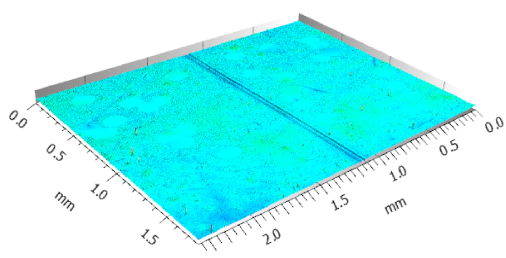

(b)

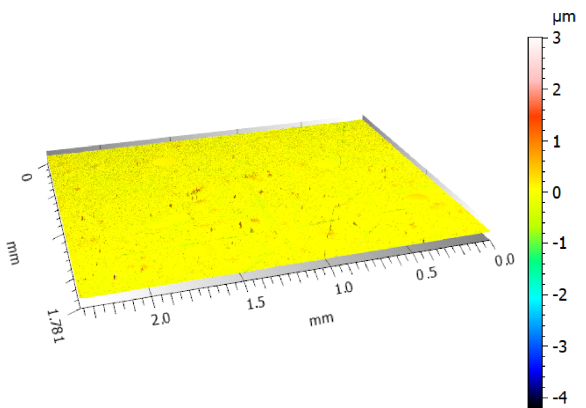

(c)
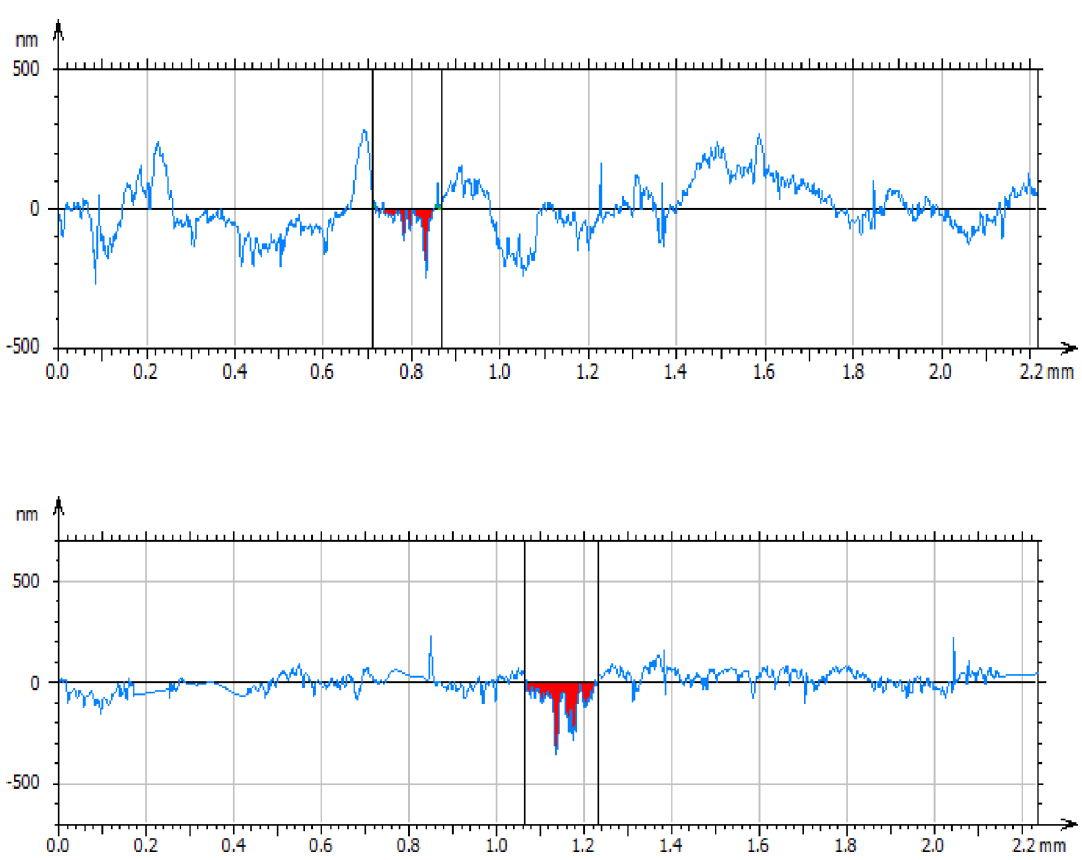

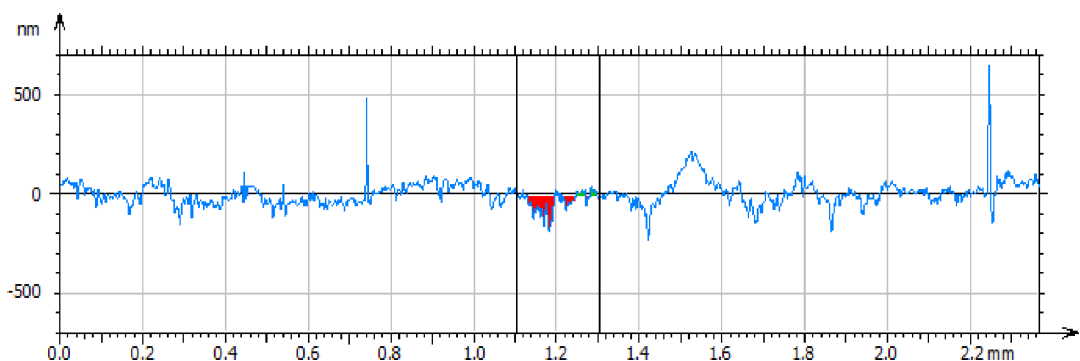

Figure 15: The isometric image of the trace of wear and the wear profile in a cross-section for Ti13Nb13Zr a-C:H a) TDF, b) RS, c) SF

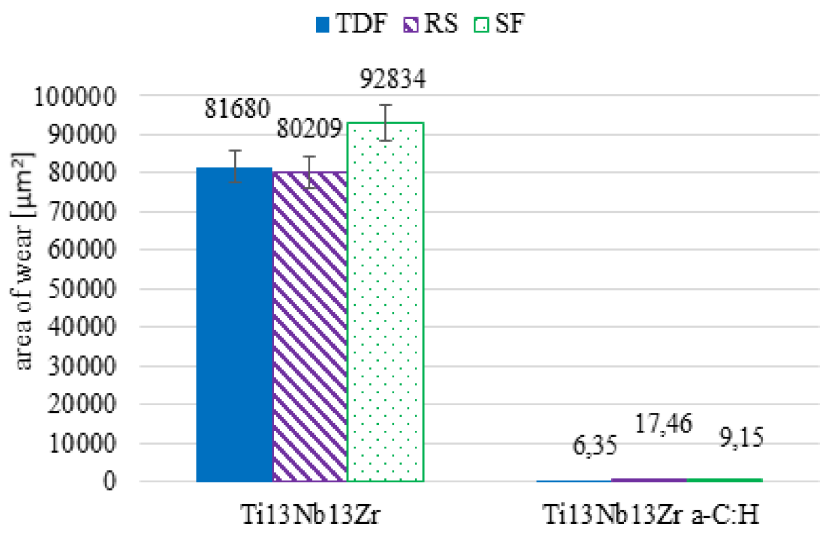

Figure 16: The area of wear in a cross-section

\section{Conclusion}

The results of nano-hardness measurements showed that as a result of diamond-like coating deposition there was an $80 \%$ increase in hardness. Moreover, it was observed that the Ti13Nb13Zr substrate is characterized by high plasticity and the a-C: H-type coating by elasticity. Tests of adhesion of the diamond-like layer showed that the mean critical force at which the first cracking of the coating occurs $\left(\mathrm{L}_{C 1}\right)$ is $2.95 \mathrm{~N}$, while the total delamination of the layer occurs at a force of $9.86 \mathrm{~N}$. It was also observed that the destruction of the coating had the character of adhesive cracks. Among all investigated material pairs, the best tribological characteristics were obtained for Ti13Nb13Zr and a-C: $\mathrm{H}-\mathrm{Al}_{2} \mathrm{O}_{3}$ using Ringer's solution as lubrication. The obtained results showed that the application of DLC coat- 
ings significantly increased the hardness and reduced the friction pair movement resistance. The analysis of the morphology of wear trace and geometric structure of the surface after tribological tests revealed high wear resistance of the a-C:H type coating.

\section{References}

[1] Forsich C, Heim D, Mueller T. Influence of the deposition temperature on mechanical and tribological properties of a-C:H:Si coatings on nitrided and postoxidized steel deposited by DCPACVD. Surf Coat Tech 2008;203:521-5.

[2] Madej M, Ozimina D, Kurzydłowski K, Płociński T, Wieciński P, Styp-Rekowski M. Some operational features of coating obtained with PACVD method. J. Mech. Eng. 2012;12:53-66.

[3] Pawelec K, Baranowicz P, Wysokińska-Miszczuk J, Madej M. The influence of diamond-like coatings on the properties of titanium. MRF. 2018;5:84-9.

[4] Zimowski S, Kot M, Moskalewicz T. The effect of mec nanoparticles on the micromechanical and tribological properties of carbon composite coatings. Tribologia. 2018;4:157-63.

[5] Gałuszka G, Madej M, Ozimina D, Kasińska J, Gałuszka R. The characterisation of pure titanium for biomedical applications. MJoM. 2017;56:191-4.

[6] Catania G, Strozzi M. Damping Oriented Design of Thin-Walled Mechanical Components by Means of Multi-Layer Coating Technology. Coatings. 2018;8;73.

[7] Balandin A. Thermal properties of graphene and nanostructured carbon materials. Nat. Mater. 2011;10:569-81.
[8] Posti E, Nieminen I. Influence of coating thickness on the life of TiN - coated high speed steel cutting tools. Wear. 1989;129:27383.

[9] Chronowska-Przywara K, Kot M, Zimowski S. Research techniques in the analysis of mechanical and tribological properties of thin layers and coatings. Scientific notebooks of the SUT. 2014;83:39-49.

[10] Kot $M$. Deformations and fracture analysis of coating-substrate systems using indentation method with different indenter. Tribologia. 2011;2:47-60.

[11] PN-EN ISO 14577-1:2015-09. Metallic materials - Instrumented indentation test for hardness and materials parameters - Part 1: Test method

[12] Schuh AC. Nanoindentation Studies of Materials. Mater. Today. 2006;9:32-40

[13] Sakharova NA, Fernandes JV, Antunes JM, Oliveira MC. Comparison between Berkovich, Vickers and conical indentation tests: A three-dimensional numerical simulation study. Int J Solids Struct. 2009;46:1095-104.

[14] Tarnowski J, Gawędzki W, Kot M. Study of the modulus of elasticity and the microhardness changes of nikasil coatings in cylinder sleeves of combustion engines due to wear. Tribologia. 2015;3:183-92.

[15] Maszybrocka J, Cybo J, Barylski A. The applications of microindentation for an assessment of radiation modification of UHMPE from the acpect of reducing the effects of plastic deformation od polimer elements of endoprotheses. Technical transactions Mechanics. 2009;3:215-19.

[16] Li XX, He JH. Nanoscale adhesion and attachment oscillation under the geometric potential. Part 1: The formation mechanism of nanofiber membrane in the electrospinning. Results in Physics. 2019;12:1405-10. 